\title{
An Overview of Radioactive Waste Disposal Research Activities Linked to International Underground Research Laboratories
}

\author{
Jens Birkholzer \\ Lawrence Berkeley National Laboratory
}

GSA 2016, Denver, Colorado 


\section{R\&D Needs for Mined Geologic Disposal}

- Understanding Geologic Disposal Safety

- Characterize geologic and hydrogeologic conditions

- Evaluate near-field perturbations

- Understand barrier integrity over time

- Predict radionuclide transport

- Demonstrate integrated system behavior

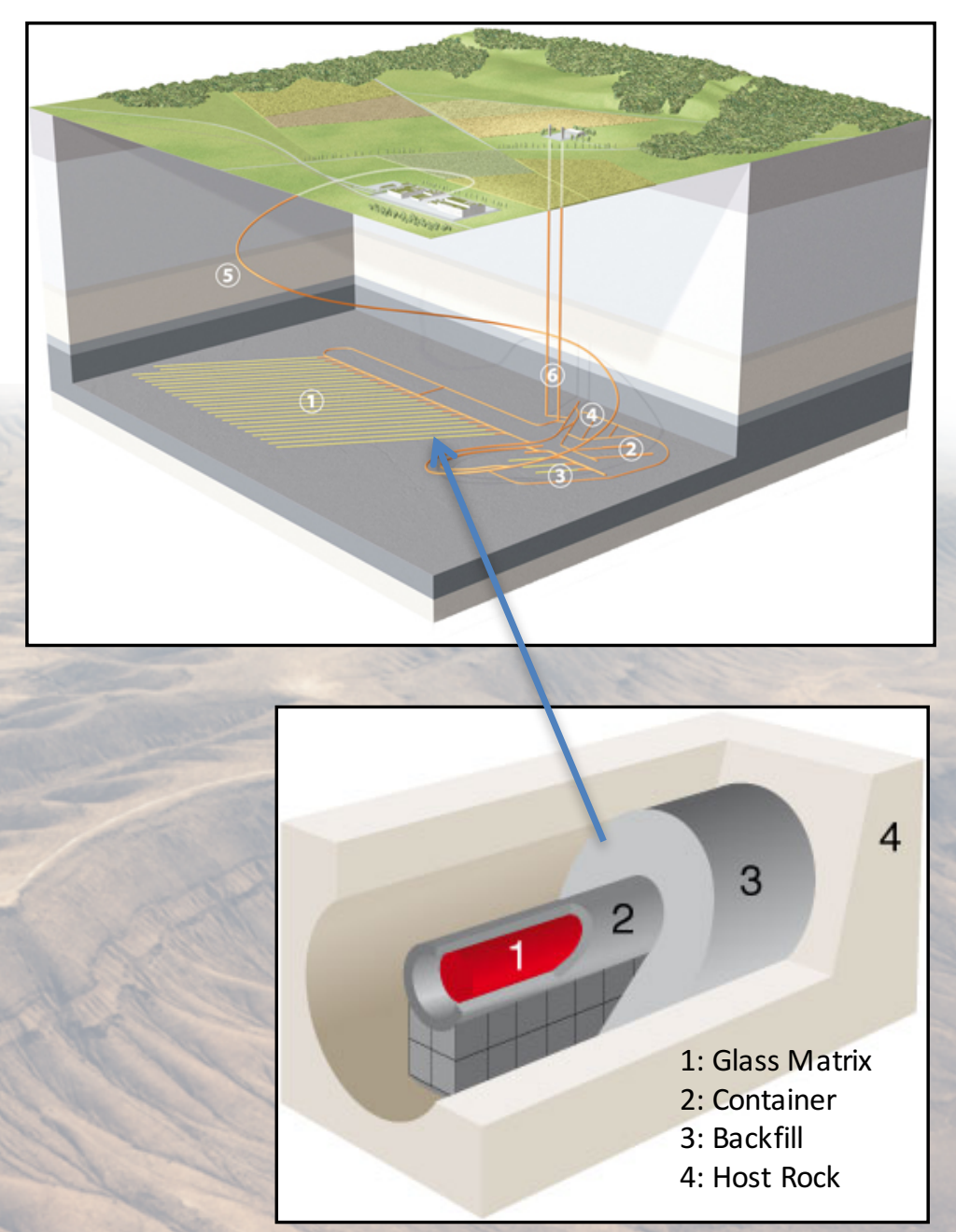




\section{Dedicated Underground Research Laboratories}

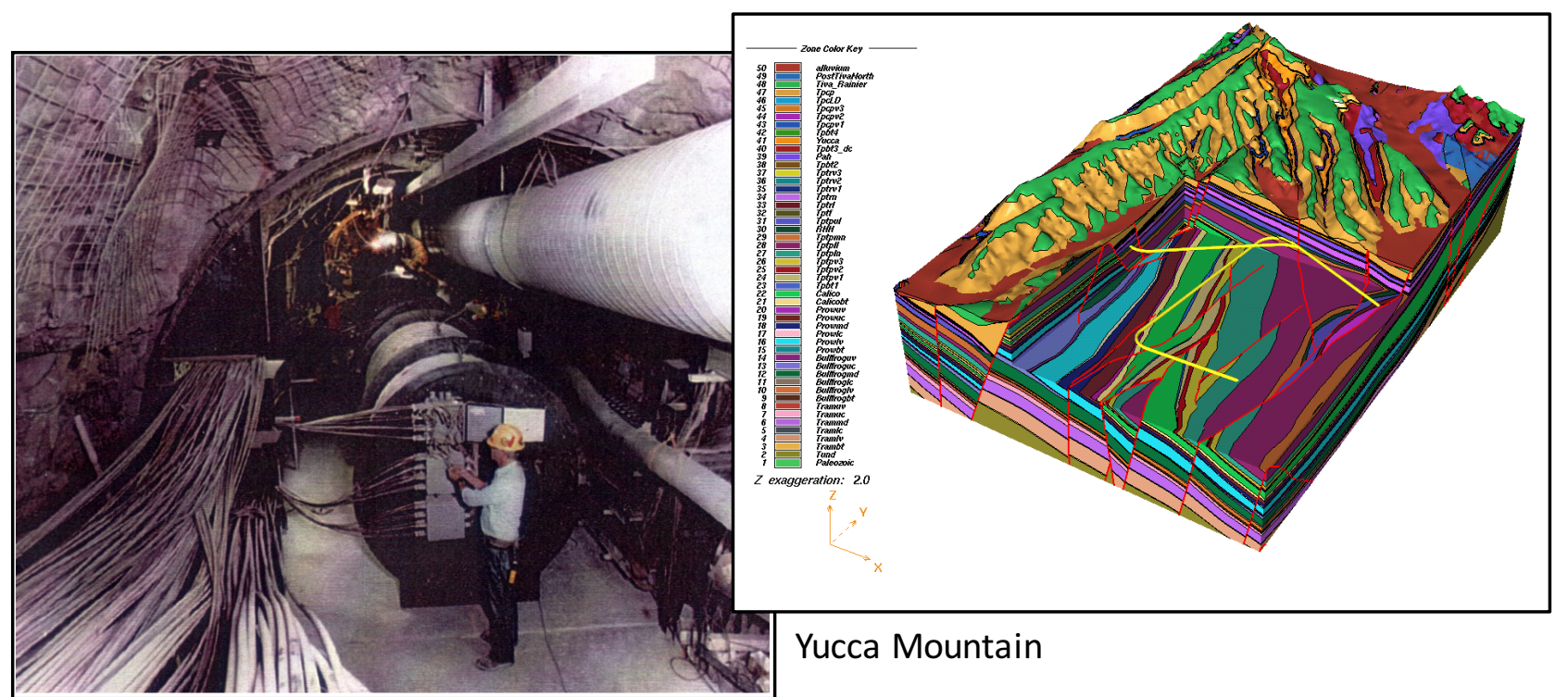

Stripa Mine

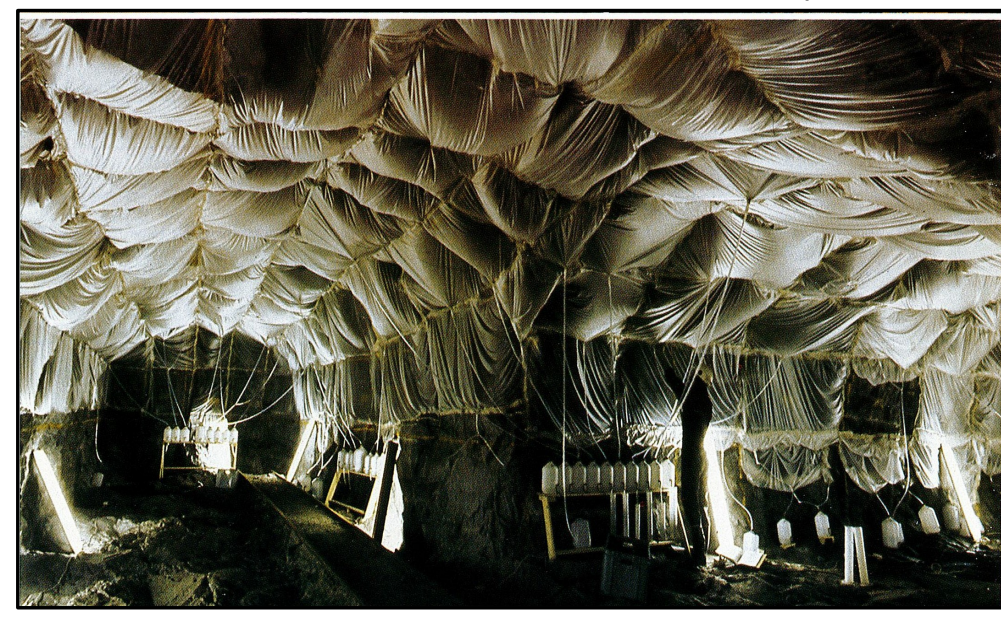

\section{Long History of Underground Observatories for Nuclear Waste Disposal R\&D}




\section{Dedicated Underground Research Laboratories}

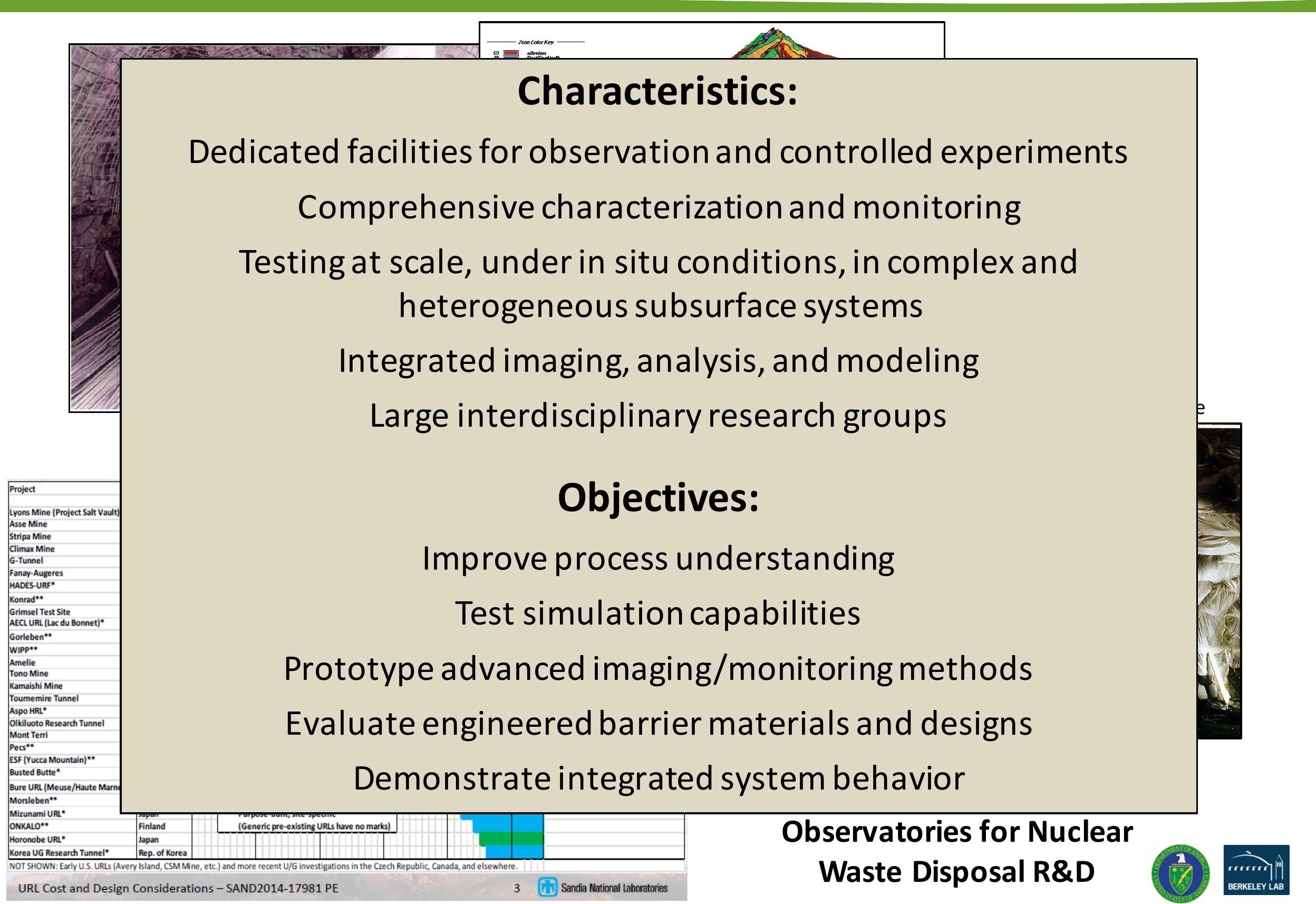




\section{U.S. DOE - Strategic Plan for International Collaboration}

- Yucca Mountain was so unique with respect to design and geologic environment that overlap with international R\&D was quite limited in the past

- With the need for addressing alternative disposal designs and geologic environments, DOE views international collaboration as a very beneficial strategy of advancing disposal R\&D

- A strategic decision was made in 2012 to advance international collaboration in disposal research, with particular focus on participation and active R\&D associated with underground research laboratories

\section{Office of Used Nuclear} Fuel Disposition winternational Program

Strategic Plan April2012

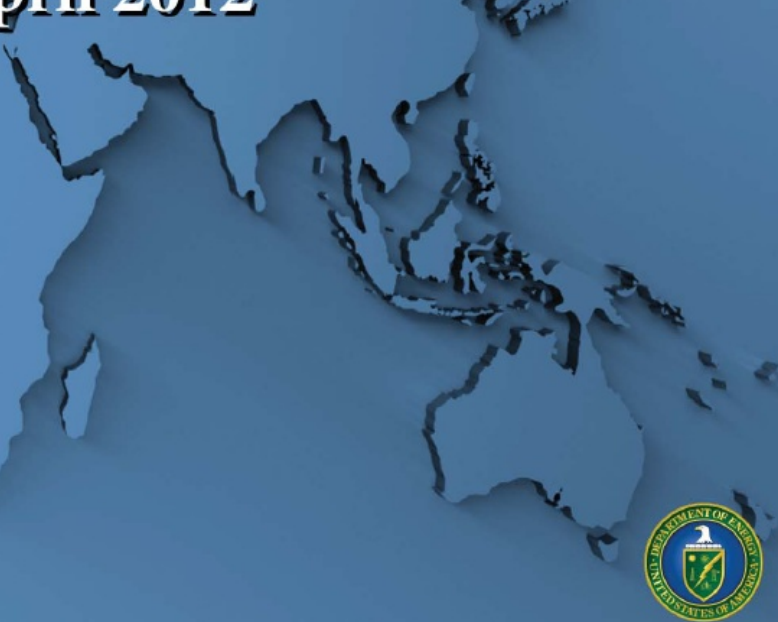




\section{Current Collaboration in International Partnerships}

\section{Multinational Initiatives}

\section{$\square \quad$ Mont Terri Project}

- Participate in experiments at Mont Terri clay URL in Switzerland

\section{$\square$ DECOVALEX Project}

- Participate in model comparison initiative for several URL related tasks in different host rocks

$\square$ Colloid Formation and Migration Project (2012-2015)

- Participate in colloid research at Grimsel granite URL in Switzerland

$\square \quad$ SKB Task Forces

- Participate in crystalline rock research centered around Äspö HRL in Sweden and Onkalo URL in Finland

$\square$ FEBEX DP

- Participate in FEBEX dismantling project, which will analyze bentonite-rock behavior after 17 years of heating

Nuclear Energy Agency (NEA)

- Thermochemical Database Project

- Salt Club

- Clay Club

\section{Bilateral Agreements}

$\square$ US-China

- Bilateral Civil Nuclear Energy Cooperative Action Plan (BCNECAP) with working group in Spent Fuel Storage and Repository Science

$\square \quad$ US-Germany benchmarking study for salt

- Participate in model comparison for TM behavior of domal and bedded salt

$\square \quad$ US-Republic of Korea (ROK)

- KAERI Underground Research Tunnel (KURT), experiments in crystalline rock

- Joint Fuel Cycle Study (JFCS), information exchange in used fuel disposal

$\square \quad$ Other Potential Opportunities

- Explore use of existing Memorandum of Understanding (MoU) between DOE and Spain (ENRESA), France (ANDRA), Japan (JNEAP) and Belgium 


\section{Mont Terri Project}

- International research project for hydrogeological, geochemical, and geotechnical studies in a clay/shale formation

- Access to experimental data from one URL, with many past, ongoing and future experiments addressing various FEPs

- URL is situated near the town of St Ursanne in Northwestern Switzerland

- Opportunity to participate directly in international research groups that conduct, analyze, and model experiments

- Opportunity for conducting own experiments
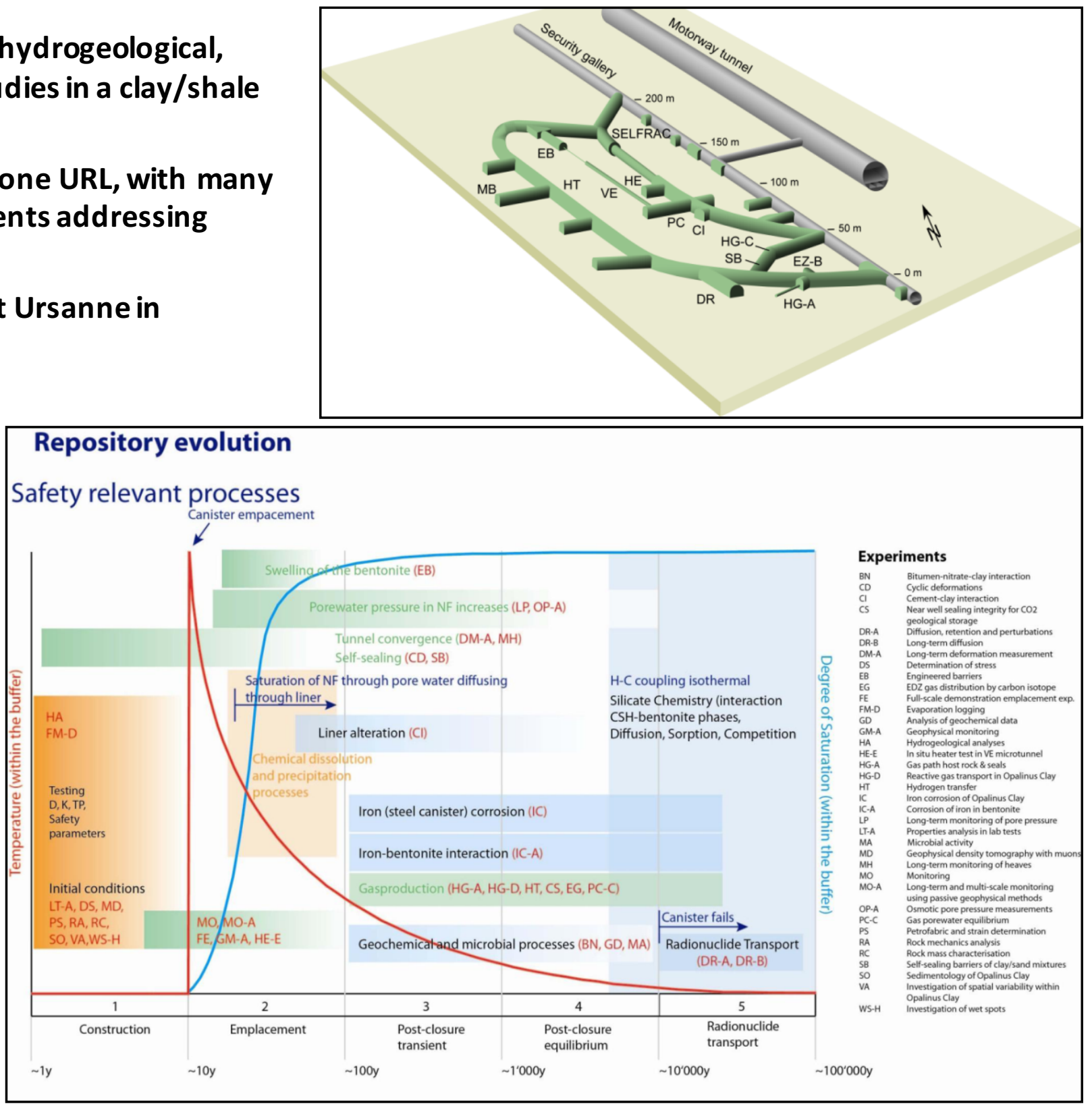


\section{Selected Mont Terri Experiments and Activities}
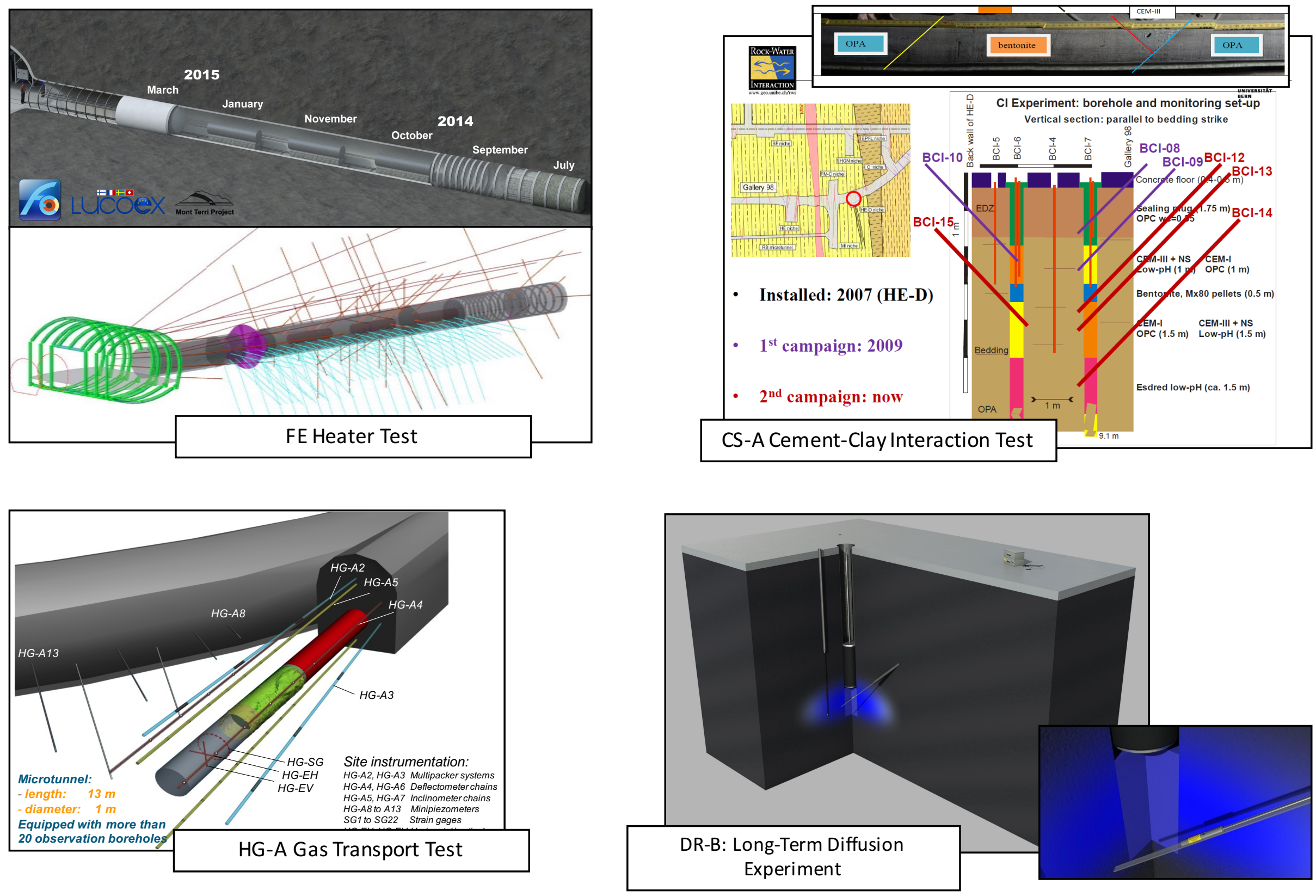


\section{DECOVALEX Model Comparison Project}

- DECOVALEX was established in 1992, and has been active since, in several project stages

- The objective is to achieve a better understanding and improved modeling of the effects of coupled (T-H-M-C) processes in nuclear waste repositories

- Past DECOVALEX activities have included several international programs and research tasks with focus on clay and granite repositories

- New DECOVALEX Phase has just started, with a kick-off meeting in Berkeley (DECOVALEX 2019)

\section{- DECOVALEX 2019 Tasks from Different URLs (examples)}

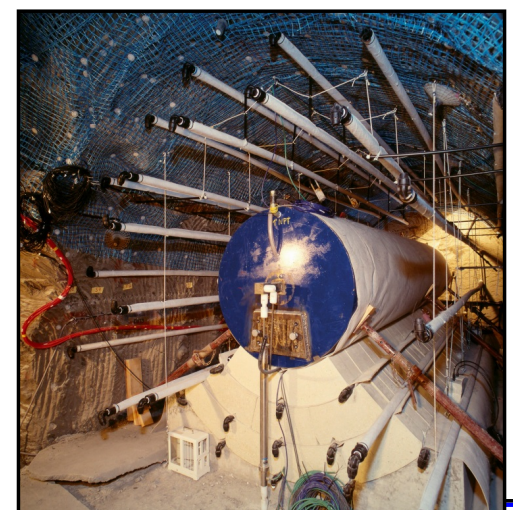

Bentonite Homogenization
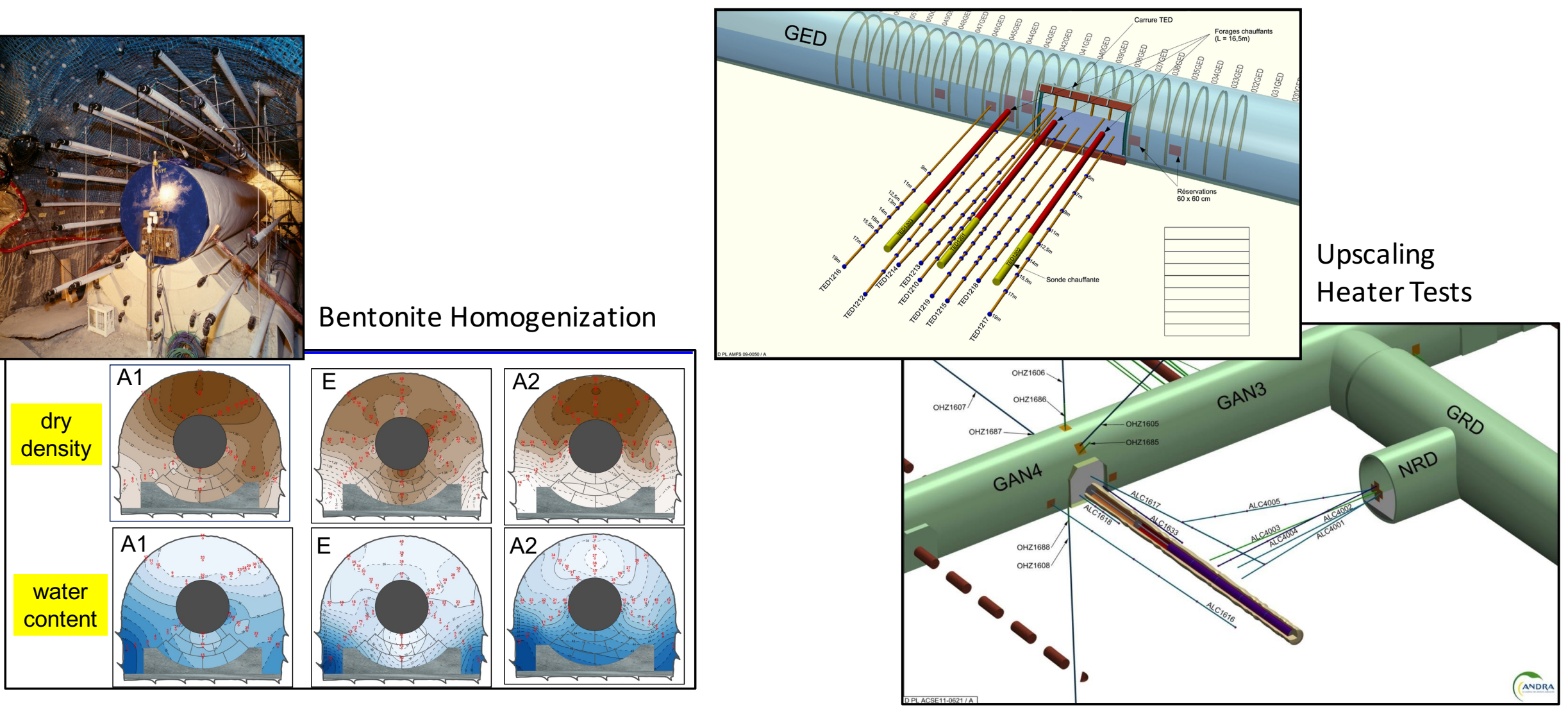


\section{DECOVALEX Characteristics}

\section{Advanced experiments}

\begin{tabular}{|l|l|l|l|l|}
\hline & & \\
\hline
\end{tabular}

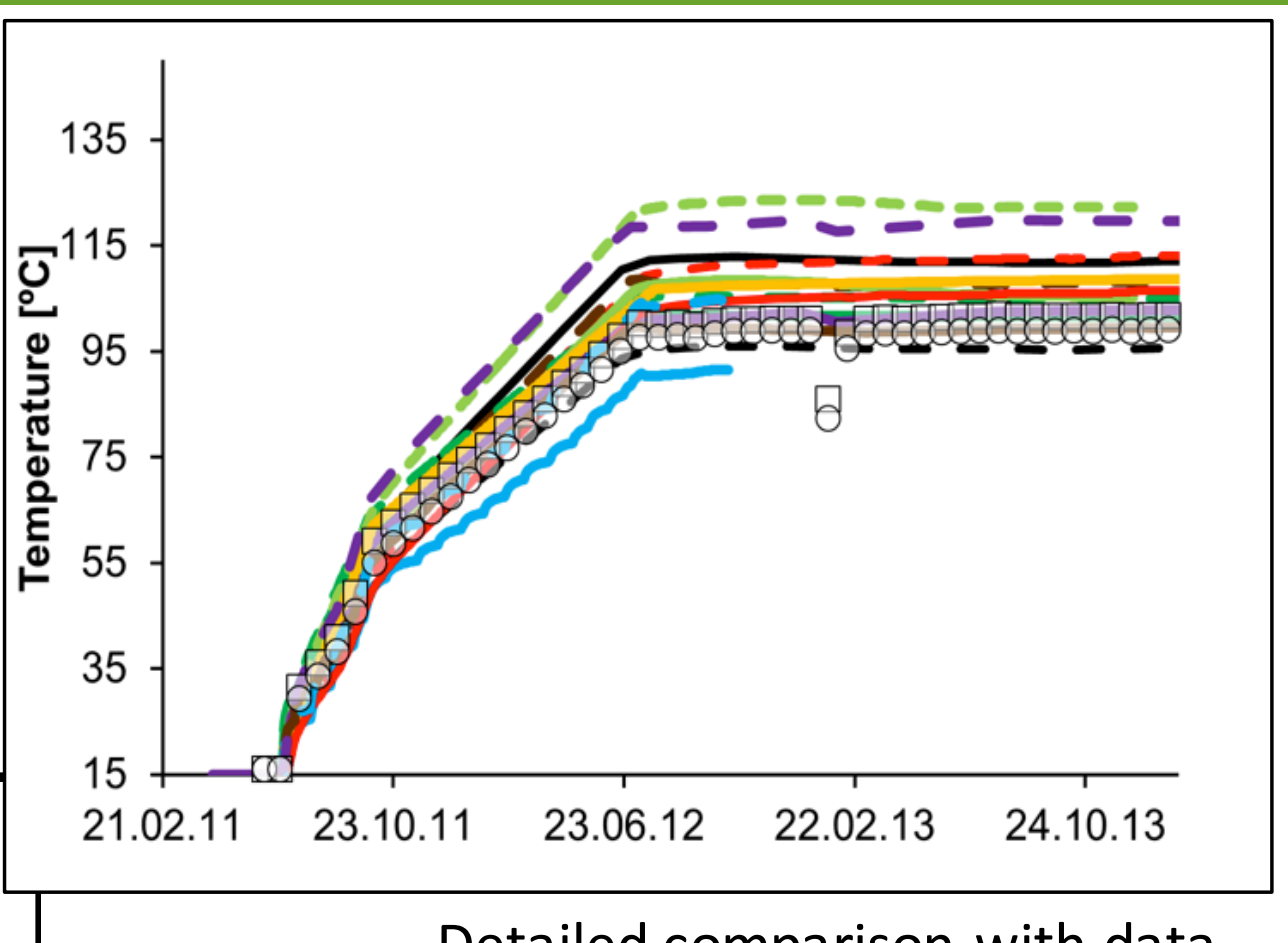

Detailed comparison with data

Various teams with various models 


\section{DECOVALEX Fault Slip Task: An Open Invitation}

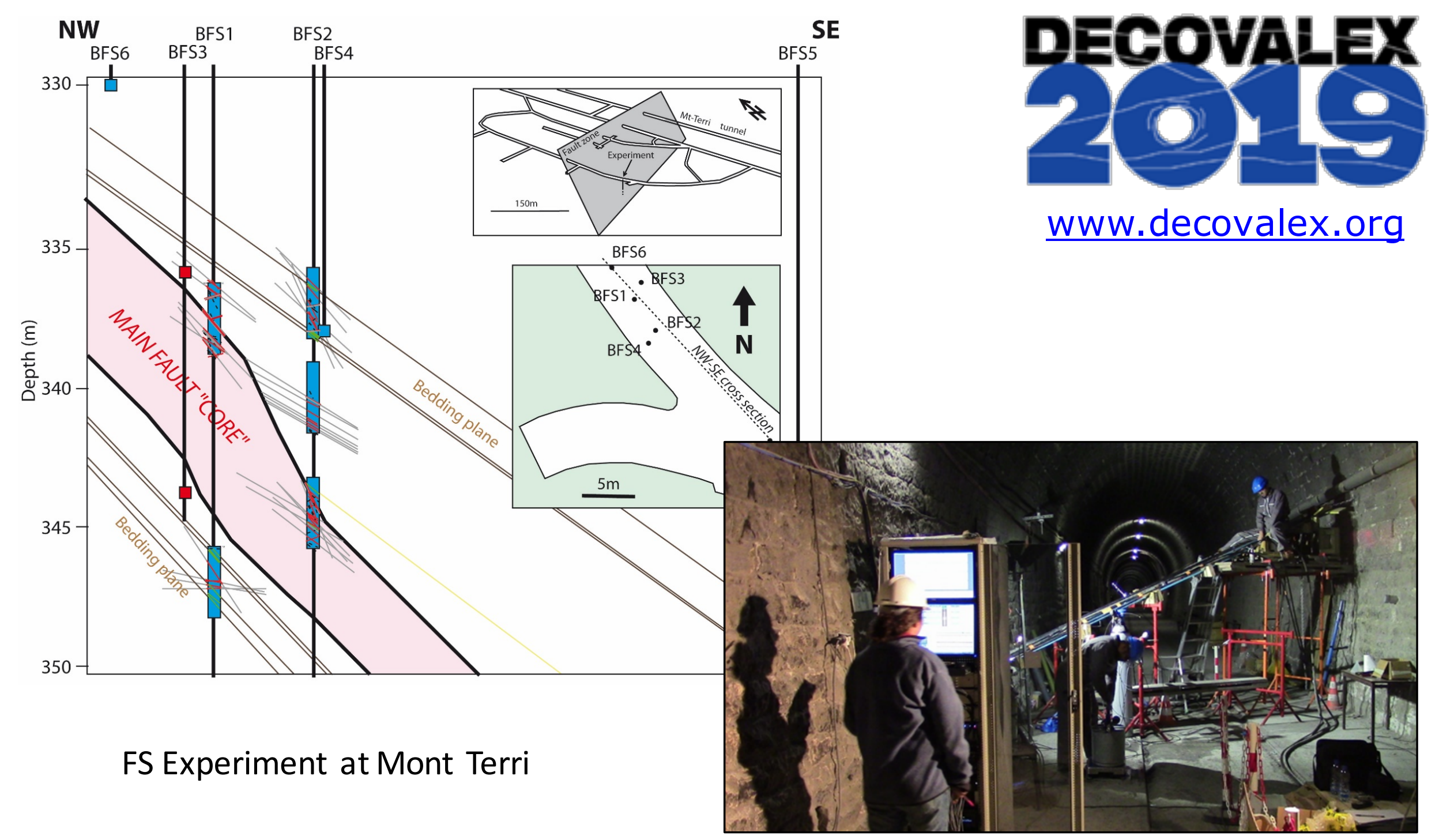

Energy

Geosciences
Contact:

Jens Birkholzer, jtbirkholzer@lbl.gov Alex Bond, alexbond@quintessa.org 


\section{Other Collaboration Examples}

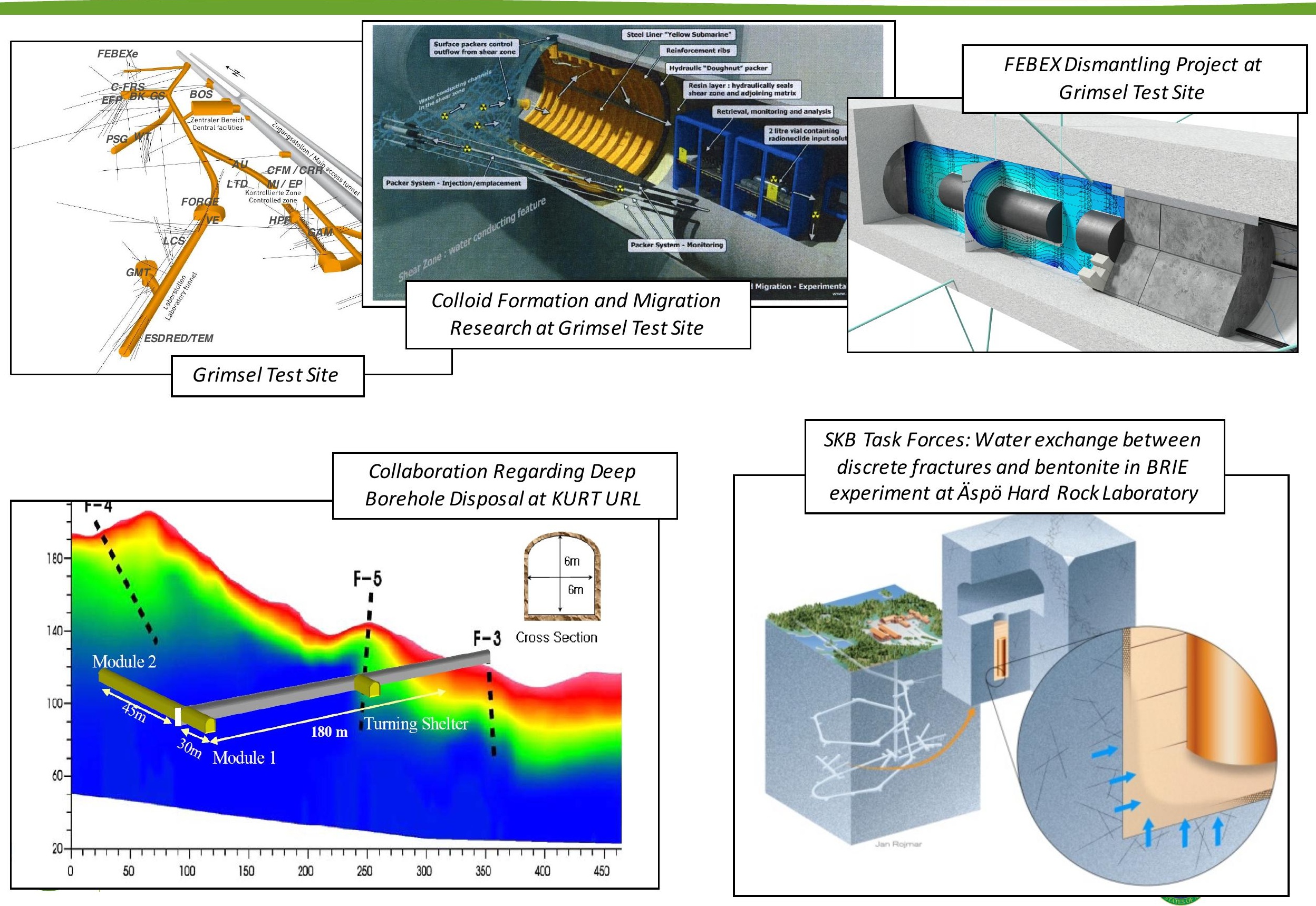




\section{Planning for New Opportunities: HotBENT}

A planned collaboration project, led by NAGRA, to conduct a joint experiment integrated with lab and modeling studies to evaluate buffer behavior at $150^{\circ} \mathrm{C}$ to $200^{\circ} \mathrm{C}$

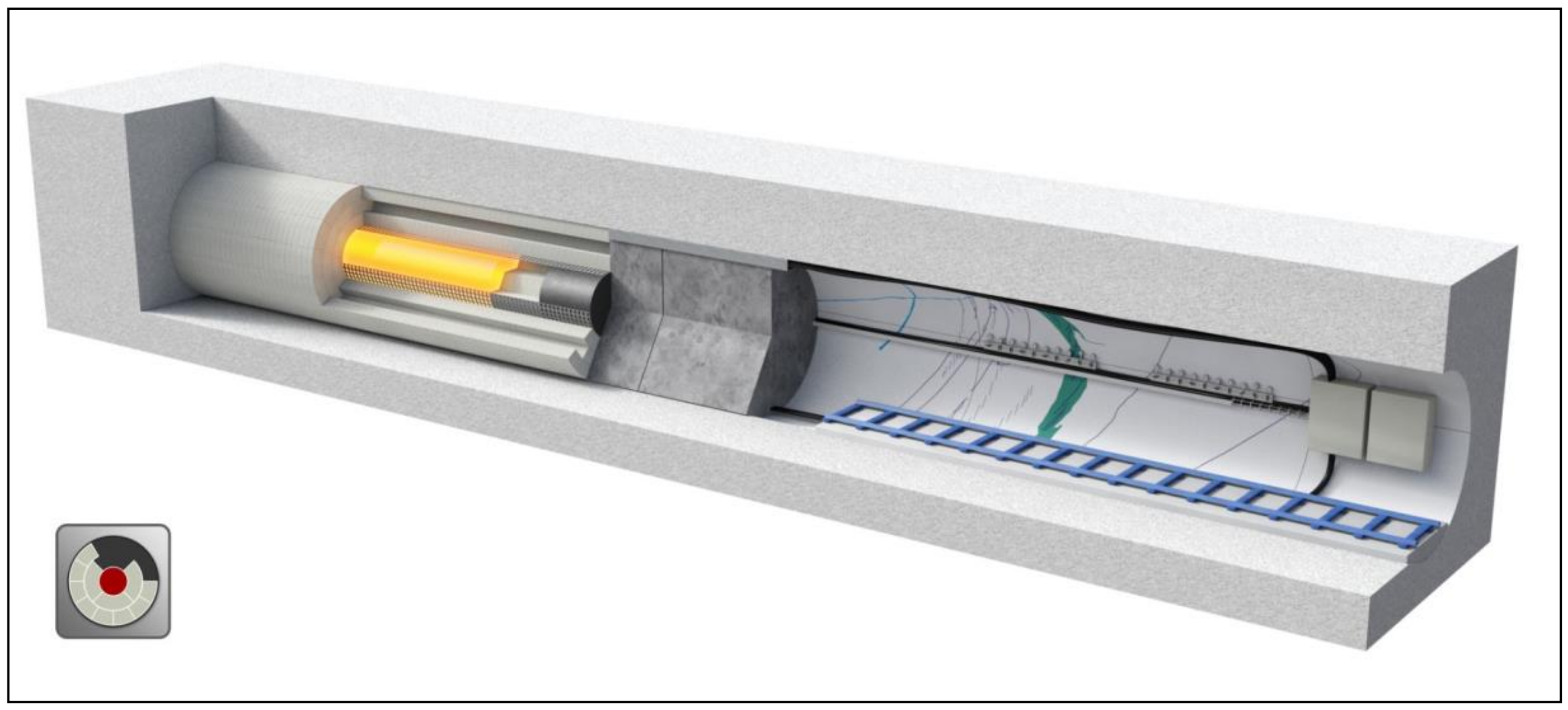




\section{Subsurface Observatories.... Build Science Communities}

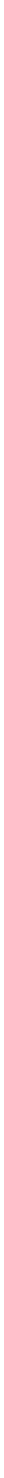




\section{Summary and Conclusions}

- Active collaboration with international programs, initiatives, or projects is beneficial to DOE's disposal research program, providing access to decades of experience gained in various disposal environments

- DOE has pursued various avenues for international collaboration and has joined formal collaborative R\&D agreements with international partners

- Focus is on partnerships that allow "active" R\&D collaboration in underground research laboratories

$>$ Improved understanding of near-field perturbation, engineered barrier integrity, and RN transport

$>$ Testing of advanced computational tools against experimental data at scale

$>$ Collaboration with international partners builds science communities and provides opportunities for learning 


\section{Backup}




\section{Borehole-Based Subsurface Observatories - cosC in Sweden}

- COSC stands for "Collisional Orogeny in the Scandinavian Caledonides" and is a scientific deep drilling project in Sweden

- COSC-1 is a 2,500 m deep borehole in crystalline bedrock fully cored and available for pilot testing of characterization methods

Swedish and US researchers recently conducted a FEC logging campaign at COSC-1 to test capability for finding inflow zones
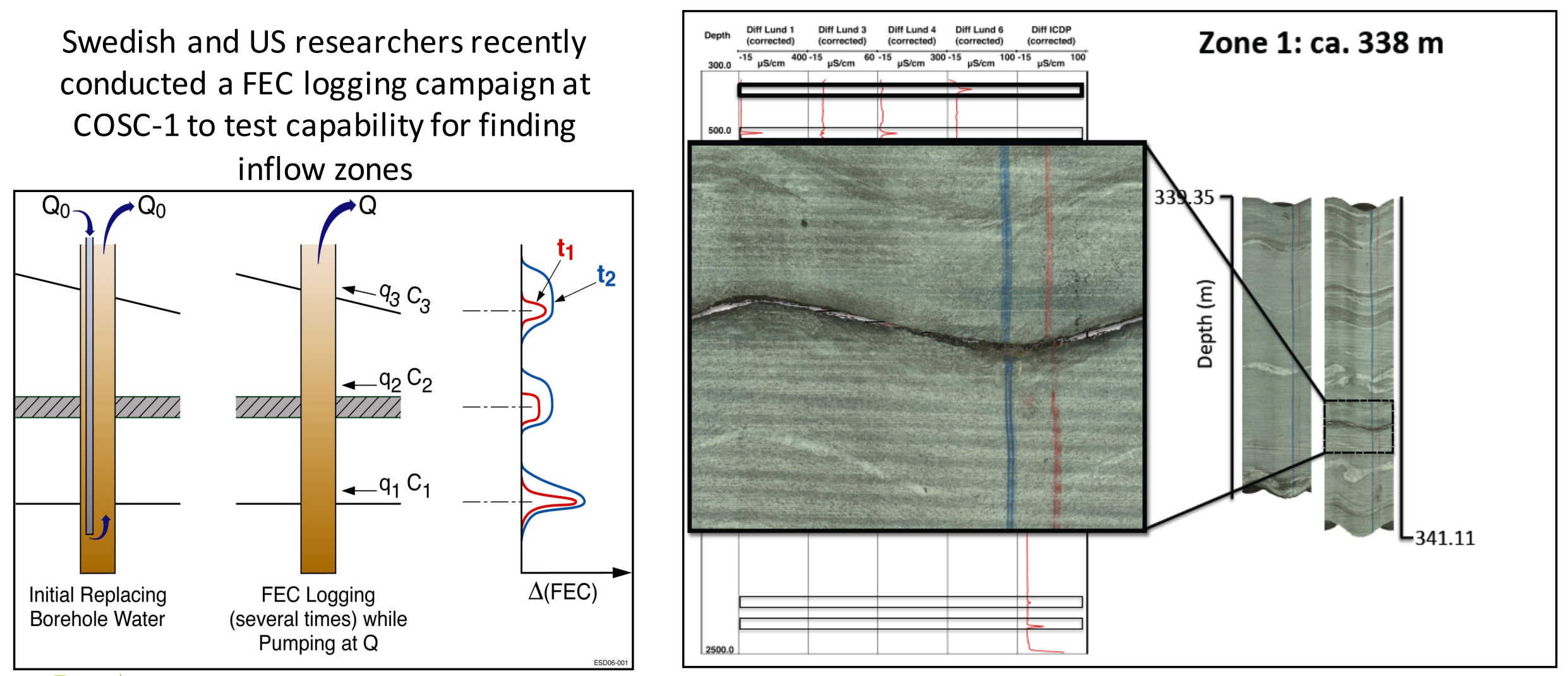


\section{Subsurface Observatories in Other Communities}
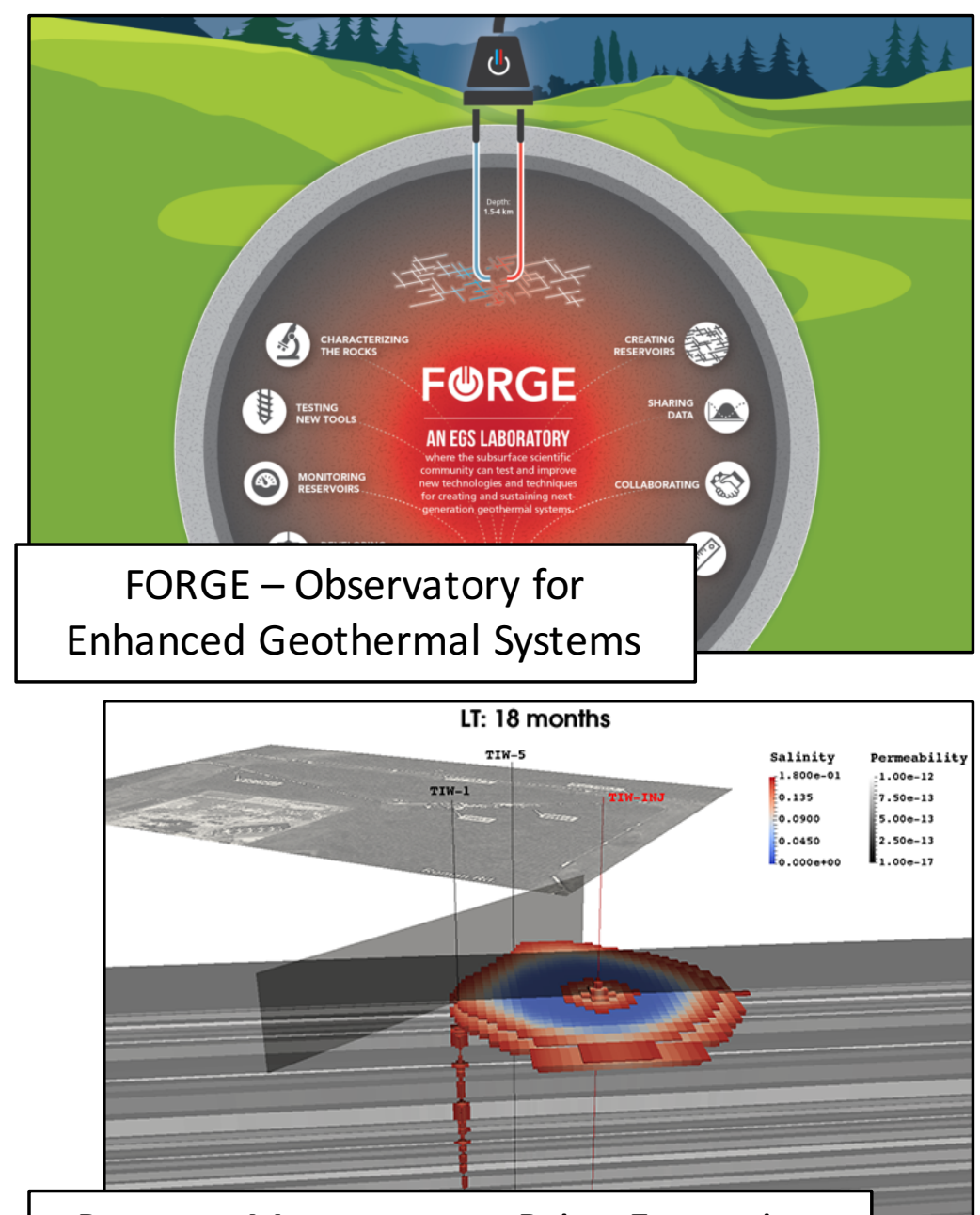

Pressure Management, Brine Extraction and Desalination Pilot Test for $\mathrm{CO}_{2}$ Storage
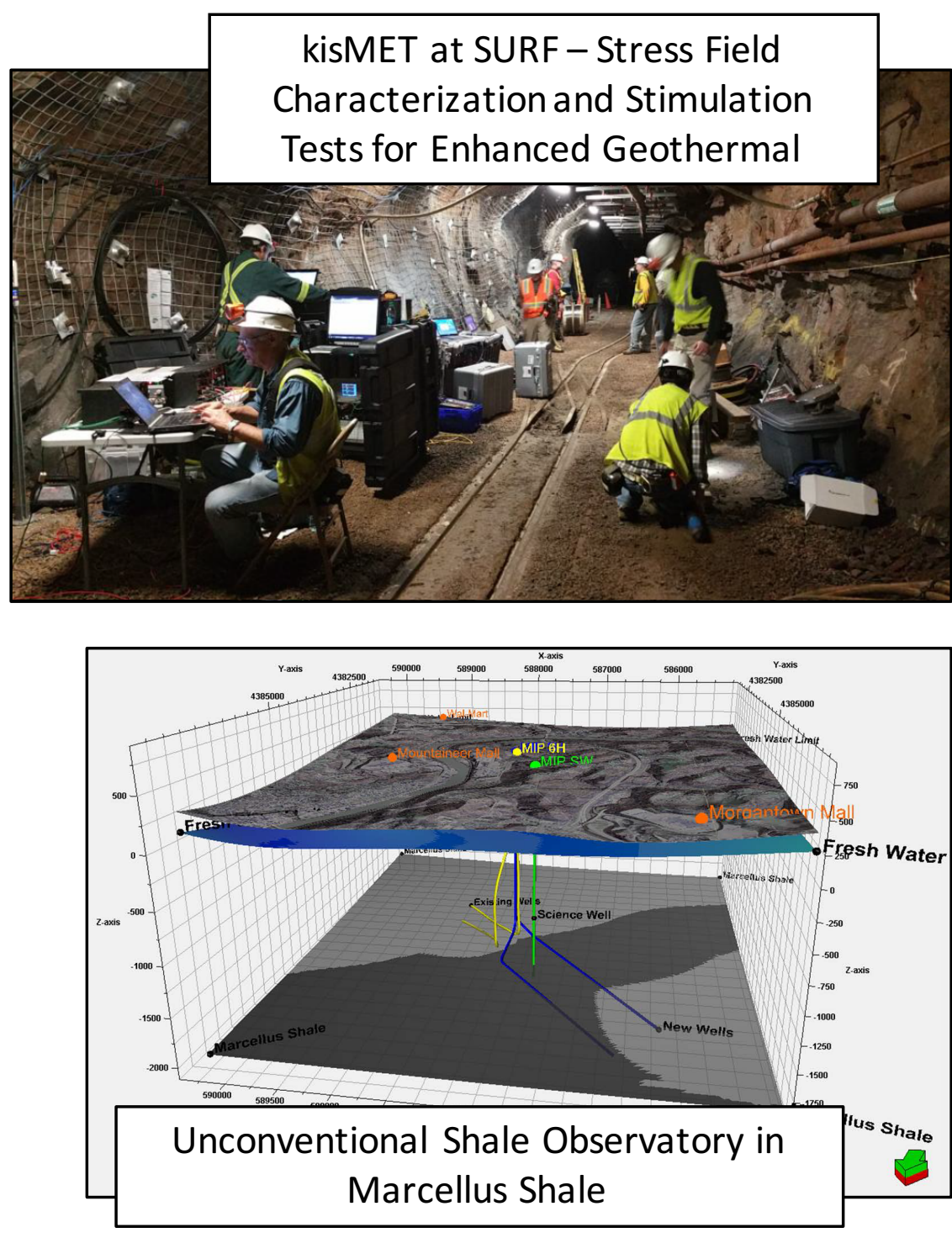